\title{
PRODUÇÃO ENXUTA NO SETOR DE SERVIÇOS: CASO DO HOSPITAL DE CLÍNICAS DE PORTO ALEGRE - HCPA
}

\section{LEAN PRODUCTION IN SERVICE SECTOR: CASE HOSPITAL DE CLÍNICAS DE PORTO ALEGRE - HCPA}

\author{
Lisiane Priscila Roldão Selau ${ }^{1}$; Mônica Gisele Brancher Pedó ${ }^{2}$ : Daniela dos Santos Senff ${ }^{3}$; Tarcisio Abreu \\ Saurin $^{4}$ \\ ${ }^{1}$ Federal University of Pelotas - UFPel - Porto Alegre - Brasil lisianeselau@gmail.com \\ ${ }^{2}$ Federal University of Rio Grande do Sul - UFRGS - Porto Alegre - Brasil monicapedo@terra.com.br \\ ${ }^{3}$ Federal University of Rio Grande do Sul - UFRGS - Porto Alegre - Brasil danisenff@terra.com.br \\ ${ }^{4}$ Federal University of Rio Grande do Sul - UFRGS - Porto Alegre - Brasil saurin@ufrgs.br
}

\begin{abstract}
Resumo
O setor de serviços vem apresentando um rápido crescimento na economia mundial, o que tem feito com que as empresas busquem se manter competitivas eliminando desperdícios e reduzindo custos, além de estar otimizando seus processos. A utilização de técnicas e ferramentas da produção enxuta, que até então eram exclusivas das manufaturas, vêm crescendo rapidamente em empresas de serviços como, por exemplo, no setor da saúde. Desenvolver um fluxo enxuto de valor expõe as fontes dos desperdícios, significando que as pessoas em todas as funções do negócio podem ter que mudar os seus hábitos. O presente artigo visa diagnosticar a aplicabilidade dos princípios da produção enxuta em uma empresa prestadora de serviços de saúde, analisando as possibilidades de melhorias e de utilização de princípios enxutos nos processos existentes através do mapeamento do processo. Constata-se que é promissora a adaptação da produção enxuta para incrementar a qualidade e o desempenho do setor de serviços.
\end{abstract}

Palavras-chave: produção enxuta, serviço enxuto, gestão de serviços, mapeamento de processos, hospitais.

\section{Introdução}

A indústria de serviços tem apresentado um expressivo crescimento que se relaciona com o aumento da terceirização. Existem atividades que não fazem parte do foco do negócio da empresa e que podem ser executadas por quem possui competência para fazer com melhor qualidade e com menores custos. Segundo Fitzsimmons e Fitzsimmons (2005), no início do século XXI, somente três em cada dez trabalhadores nos Estados Unidos estavam empregados no setor de serviços. Hoje, o setor de serviços emprega oito em cada dez trabalhadores e em países como os Estados Unidos e Canadá, geram $74 \%$ do produto interno bruto. Durante os últimos 90 anos, foi observada uma 
importante evolução na economia mundial que deixou de ser baseada em manufatura para ser predominantemente baseada em serviços.

Algumas características associadas à definição de serviços são importantes para entender suas peculiaridades e diferenciá-lo de produtos. Os serviços são intangíveis, ou seja, não podem ser consumidos, tocados ou provados antes de serem comprados, o que torna a avaliação do cliente muito subjetiva. Além disso, os serviços são inseparáveis, sendo produzidos e consumidos simultaneamente e, como conseqüência, não existe oportunidade de inspeção final antes da entrega. Os serviços também são perecíveis, não podendo ser estocados, o que dificulta o uso eficiente da capacidade produtiva, que se não for utilizada, pela inexistência de demanda, é perdida para sempre. Como última característica tem-se que os serviços são variáveis, já que dependem de quem os executa e onde são processados, dificultando o controle de qualidade, e por isso, se faz necessário muito investimento em treinamento e padronização (FITZSIMMONS; FITZSIMMONS, 2005).

O reconhecimento das características especiais da prestação de serviços e a sua comparação com o setor de manufatura constituem a base para um gerenciamento inovador e potencialmente otimizado. Assim como na manufatura, o cliente não quer pagar pelo desperdício ou pela falta de eficiência da empresa, o que torna essencial implementar continuamente melhorias nos processos e a melhoria do aproveitamento dos recursos. Neste sentido, é possível identificar a crescente aplicação de conceitos da produção enxuta para serviços em setores como saúde, seguros, finanças e assistência técnica (WOMACK et al., 1992).

A produção enxuta é definida com um "sistema de negócios para organizar e gerenciar o desenvolvimento de produtos, operações, fornecedores e relações com o cliente" (MARCHWINSKI; SHOOK, 2003, p.63). Mais do que uma ferramenta de gestão da produção, a produção enxuta é um modo de pensar.

Mesmo tendo sido desenvolvida com um foco industrial, a produção enxuta é passível de aplicação em qualquer setor, inclusive no de serviços, visto que permite alcançar altos níveis de qualidade, baixos custos e prazos de entrega adequados (ÅHLSTRÖM, 2004; WOMACK; JONES, 2005; SWANK, 2003; FERRO, 2008). Assim sendo, o objetivo deste trabalho é diagnosticar a aplicabilidade dos princípios da produção enxuta em um hospital, analisando as possibilidades de melhorias e de utilização de princípios enxutos através do mapeamento dos processos.

\section{Princípios da Produção Enxuta em Serviços}

Todas as áreas da empresa podem se beneficiar da aplicação de princípios enxutos, assegurando custos mais baixos, serviços de alta qualidade, e entrega de melhores serviços no tempo e nos padrões desejados pelo cliente. A adaptação dos conceitos de produção enxuta para o 
setor de serviços é chamada de Lean Service (Serviço Enxuto) (ÅHLSTRÖM, 2004).

Embora a produção enxuta seja usualmente vista como um conceito de manufatura, muitas de suas ferramentas foram desenvolvidas nas indústrias de serviço (SWANK, 2003). Por exemplo, o conceito dos supermercados, existente há mais de 40 anos, e não deixa de ser uma área de estocagem onde as pessoas compram os materiais e componentes que estão precisando.

Segundo Bowen e Youngdahl (1998), uma diferença fundamental entre a produção enxuta e a abordagem enxuta para serviços é que esta última ocorre na presença do consumidor/cliente, enquanto que em uma manufatura típica isto não acontece. Os autores apresentaram o exemplo bem sucedido do Shouldice Hospital, que mostra a abordagem enxuta aplicada não só na padronização e eficiência dos setores de apoio, mas conseguindo a extensiva participação dos pacientes para atingir estes objetivos também na preparação e realização das cirurgias e nas fases de recuperação. Outros resultados alcançados pelo Shouldice com a utilização da abordagem enxuta foram redução de custos e melhora expressiva nas taxas de recuperação dos pacientes (mais rápido e com menores complicações).

Os princípios do pensamento enxuto devem ser aplicados aos processos de consumo das empresas de serviço e isto significa resolver o problema do consumidor completamente, assegurando que todos os serviços funcionem juntos; não desperdiçar o tempo e nem o esforço do consumidor; prover exatamente o que o consumidor quer, onde é ele quer e quando ele quer. Isto irá requerer que as empresas e seus fornecedores determinem como configurar processos e atividades ligados entre si, principalmente entre empresas para atender as necessidades dos consumidores sem desperdiçar o seu próprio (e muito menos de seu consumidor) tempo, esforço e recursos (WOMACK; JONES, 2005).

Um quadro resumo com os princípios da produção enxuta aplicados a serviços, discutidos por diversos autores, é apresentado no Quadro 1.

Quadro 1 - Quadro Resumo de Princípios da Produção Enxuta em Serviços

\begin{tabular}{|c|c|}
\hline $\begin{array}{c}\text { WOMACK \& } \\
\text { JONES } \\
(1994)\end{array}$ & $\begin{array}{l}\text { - Eliminar passos desnecessários } \\
\text { - Alinhar todos os passos de uma atividade em um fluxo contínuo } \\
\text { - Recombinar trabalhadores em equipes multifuncionais dedicadas as atividades } \\
\text { - Continuamente empenhar-se para melhorar }\end{array}$ \\
\hline $\begin{array}{c}\text { BOWEN \& } \\
\text { YOUNGDAHL } \\
(1998)\end{array}$ & $\begin{array}{l}\text { - Reduzir os trade-offs de desempenho } \\
\text { - Fazer os processos de valor agregado fluírem e implementar sistema puxado pelo cliente } \\
\text { - Eliminar perdas na cadeia de valor das atividades, do desenvolvimento à entrega } \\
\text { - Aumentar o foco no cliente e seu envolvimento nos processos de desenvolvimento e entrega } \\
\text { - Dar poder aos funcionários e times }\end{array}$ \\
\hline $\begin{array}{c}\text { SWANK } \\
(2003)\end{array}$ & $\begin{array}{l}\text { - Alocar os processos que têm ligação próximos uns aos outros } \\
\text { - Padronizar procedimentos } \\
\text { - Eliminar loopings entre atividades } \\
\text { - Estabelecer o takt-time } \\
\text { - Balancear cargas de trabalho }\end{array}$ \\
\hline
\end{tabular}




\begin{tabular}{|c|c|}
\hline & $\begin{array}{l}\text { - Segregar as atividades por complexidade } \\
\text { - Publicar/ apresentar os resultados de performance }\end{array}$ \\
\hline \multicolumn{2}{|l|}{ (.... continuação) } \\
\hline $\begin{array}{c}\text { SÁNCHEZ \& } \\
\text { PÉREZ } \\
(\mathbf{2 0 0 4 )}\end{array}$ & $\begin{array}{l}\text { - Eliminação de perdas } \\
\text { - Melhoria contínua } \\
\text { - Equipes multifuncionais } \\
\text { - Entrega just-in-time } \\
\text { - Envolvimento de fornecedores } \\
\text { - Sistemas de informação flexíveis }\end{array}$ \\
\hline $\begin{array}{l}\text { ÅHLSTRÖM } \\
\qquad(2004)\end{array}$ & $\begin{array}{l}\text { - Eliminação de desperdícios } \\
\text { - Zero defeitos } \\
\text { - Puxar ao invés de empurrar } \\
\text { - Equipes multifuncionais } \\
\text { - Descentralização de responsabilidades } \\
\text { - Sistemas verticalizados de informação } \\
\text { - Melhoria contínua } \\
\end{array}$ \\
\hline $\begin{array}{c}\text { WOMACK \& } \\
\text { JONES } \\
(\mathbf{2 0 0 5 )}\end{array}$ & $\begin{array}{l}\text { - Resolver o problema do consumidor completamente assegurando que todos os serviços } \\
\text { funcionam e funcionam juntos } \\
\text { - Não desperdiçar o tempo do consumidor } \\
\text { - Prover exatamente o que o consumidor quer } \\
\text { - Prover o que é desejado exatamente onde é desejado } \\
\text { - Prover o que é desejado, onde é desejado e quando é desejado }\end{array}$ \\
\hline $\begin{array}{l}\text { JONES } \\
(2006)\end{array}$ & $\begin{array}{l}\text { - Especificar o que cria e o que não cria valor na perspectiva do cliente } \\
\text { - Identificar todos os passos necessários para desenhar, pedir e produzir o serviço ao longo do } \\
\text { fluxo para focalizar perdas que não adicionam valor } \\
\text { - Fazer aquelas atividades que criam valor fluir sem interrupções, retornos, esperas ou fragmentos } \\
\text { - Fazer somente o que é puxado pelo consumidor } \\
\text { - Empenhar-se pela perfeição, melhorando continuamente os serviços e o fluxo de valor }\end{array}$ \\
\hline
\end{tabular}

Fonte: Pesquisa de campo (2008)

A partir dessa comparação, decidiu-se tomar como referência os princípios sugeridos por Åhlström (2004) para diagnóstico da aplicabilidade no setor de serviços, devido a seu enfoque mais operacional e com maior ligação às típicas práticas enxutas. Estes princípios são detalhados a seguir, juntamente com exemplos da aplicação no setor de serviços hospitalares.

a) Eliminação de desperdícios - a produção enxuta considera como desperdício tudo o que não agrega valor ao produto. Uma das maiores fontes de desperdício são os estoques, sendo que as causas por trás dos estoques devem ser eliminadas. Outra fonte de desperdícios é a conferência de qualidade. Exemplos de desperdício em um hospital é subutilização de material, teste de laboratório, cirurgias e uso de medicação desnecessária e layouts que fazem pacientes moverem-se desnecessariamente.

b) Zero defeito - para atingir alta produtividade, todas as partes e produtos devem ser livres de falhas desde o seu começo. A busca pela qualidade deve ser responsabilidade de todos. Em serviços de saúde é crucial atingir o zero defeito. A qualidade dos equipamentos e medicamentos é de extrema importância, sendo, portanto, sua fabricação sujeita à altíssima qualidade. Para alcançar o zero defeito é importante que métodos, processos e procedimentos sejam bem desenvolvidos.

c) Puxar ao invés de empurrar - o ponto inicial é o pedido do cliente. Utiliza-se o controle 
de material just-in-time. Um sistema de saúde já é, por definição, caracterizado como um sistema puxado, pois não pode ser armazenado e é fornecido aos pacientes conforme sua demanda. Contudo, a maioria dos hospitais opera com um misto entre os sistemas puxado e empurrado, pois existe uma agenda de cirurgias, e os pacientes são mantidos em uma fila (virtual ou física).

d) Equipes multifuncionais - cada equipe é responsável por realizar todas as tarefas de sua etapa no fluxo e também por atividades indiretas como manutenção, qualidade, movimentação e controle de material. As equipes são unidades importantes na organização de um hospital, sendo que existem diversos tipos: equipes de cirurgiões, de enfermeiras, de atendentes, etc. É possível ter certa flexibilidade entre estes times, mas muito restrita, pois as funções são muito bem definidas e diferentes umas das outras.

e) Descentralização de responsabilidades - nos sistemas de produção enxuta, a autoridade e responsabilidade são levadas para os níveis mais baixos da organização, sendo que as atividades de supervisão são transferidas para as equipes. A descentralização de responsabilidades é considerada aplicável e apropriada às definições em um hospital, contudo um fator complicador é que os hospitais geralmente têm duas hierarquias uma profissional e uma administrativa. A redução de hierarquias poderia ser feita através da integração de atividades administrativas às tarefas diárias das equipes de atendimento.

f) Sistemas verticalizados de informação - são sistemas simples que capacitam as equipes multifuncionais a trabalharem de acordo com as metas da empresa. Trabalham em tempo real, objetivando identificar e resolver problemas. As informações são importantes em um hospital, sendo que um sistema verticalizado é válido para compartilhar informações ao longo da organização, com um foco particular em agregar valor a todos. As principais informações a serem compartilhadas seriam o fluxo do paciente, o tempo de realização de procedimentos e as notícias sobre os pacientes.

g) Melhoria contínua - o único objetivo é a perfeição, com o envolvimento dos operadores na melhoria contínua (Kaisen). Trabalhar com melhoria contínua em pequenos grupos é consideravelmente aplicável em um hospital. Normalmente já ocorrem nas rotinas internas as reuniões de departamentos e de blocos, mas elas raramente têm o foco em melhoria.

De acordo com Fitzsimmons e Fitzsimmons (2005), o controle de estoques é uma das principais questões nas operações de manufatura, enquanto que, em serviços, o problema correspondente é a espera do cliente, ou seja, as filas. Por estes motivos que, para aplicação dos princípios enxutos, é interessante a aplicação da ferramenta de mapeamento de fluxo de valor, adaptada para serviços, que será detalhada no próximo capítulo. 


\section{Mapeamento de Fluxo de Valor adaptado ao setor de serviços}

A aplicação de princípios enxutos em indústrias, em geral, é iniciada pelo Mapeamento do Fluxo de Valor (MFV) no processo produtivo. De acordo com Rother e Shook (1999), um fluxo de valor é toda ação (agregando valor ou não) necessária para trazer um produto por todos os fluxos essenciais, sendo: o fluxo de produção desde a matéria-prima até os braços do consumidor e; o fluxo do projeto do produto, da concepção até o lançamento. Os mesmos autores comentam que considerar a perspectiva do fluxo de valor significa levar em conta o quadro mais amplo, não só os processos individuais, ou seja, procura-se melhorar o todo, não só otimizar as partes.

Para utilizar o MFV no setor de serviços, Womack e Jones (2005) desenvolveram uma forma de mapeamento de processos para identificação de perdas de valor, o chamado Consumo Lean. Conforme os autores, o consumo é um processo contínuo, um conjunto de ações executadas em um determinado período, para solucionar um problema. Assim, o objetivo principal dos prestadores de serviço deve ser solucionar os problemas dos seus clientes.

Os mesmos autores citam seis princípios básicos do Consumo Lean, ou Consumo Enxuto, os quais fornecem uma definição de valores para o consumidor moderno e que devem ser atendidos pelos fornecedores: resolva completamente o problema do cliente; não desperdice o tempo do cliente (minimizar o custo total do consumo, que é o preço pago e o tempo gasto para comprá-lo); forneça exatamente o que o cliente quer; entregue o produto aonde o cliente quer; entregue o produto quando o cliente quiser; reduza o número de decisões que o cliente precisará tomar para solucionar o seu problema.

A proposta do Consumo Lean é que seja feita a lista dos passos para o consumo, o que consiste na listagem ordenada dos passos que o consumidor deve executar para consumir o serviço desejado, com os respectivos tempos gastos. Para facilitar a visualização, é recomendado o desenho do mapa do processo de consumo. O desenho deve sempre ser feito da esquerda para a direita, sendo que cada etapa deve ser representada por uma caixa, que deve ser desenhada na proporção do tempo que leva para ser executada.

Cada etapa do processo deve ser avaliada como sendo criadoras ou não de valor, ou seja, se é realmente importante para resolver o problema do consumidor. Assim, o mapa demonstra quais são os pontos que podem ser alterados para que o processo seja otimizado, do ponto de vista do cliente. A idéia é que, ao finalizar o estudo, o mapa do estado futuro tenha somente etapas criadoras de valor, o que trará maior satisfação ao cliente.

Para finalizar o mapeamento, deve-se desenhar os dois mapas, o da perspectiva do cliente e o da perspectiva do fornecedor, em paralelo, a fim de que seja possível ver o processo completo, em ambas as perspectivas. Como resultado, tem-se condições de entender quais atividades do 
fornecedor estão atingindo diretamente ou não o processo de compra do serviço, na perspectiva do cliente. Dessa forma, é possível identificar quais são as possibilidades de melhorias do processo e se há etapas que podem ser descartadas, agrupadas ou otimizadas. Com o mapa pronto e tendo as situações problemáticas identificadas, deve-se observar os princípios do Consumo Lean e tentar aplicá-los, na forma de melhorias nos processos, reduzindo os tempos gastos, em especial aqueles que não agregam valor.

Desenvolver um fluxo enxuto de valor expõe as fontes dos desperdícios, significando que as pessoas em todas as funções do negócio podem ter que mudar os seus hábitos. De acordo com Rother e Shook (1999), todos os envolvidos, administradores e colaboradores, têm um papel na implementação enxuta, sendo que todos poderão ser beneficiados por isso, devido às possibilidades de melhoria do ambiente de trabalho, maior confiança entre administradores e colaboradores, maior qualidade para o cliente e, quando for o caso, maior competitividade da organização ou redução de custos. É muito importante, portanto, que seja executado um programa de motivação de toda a equipe, em paralelo ao estudo dos processos, para que todos participem ativamente das melhorias possíveis. Muitas vezes, são os próprios funcionários que praticam as tarefas diariamente que têm as melhores idéias de otimizações possíveis.

\section{Metodologia}

O método de pesquisa utilizado foi o estudo de caso realizado no Hospital de Clínicas de Porto Alegre - RS (HCPA). O HCPA é uma empresa pública de direito privado, vinculado à supervisão do Ministério da Educação do Brasil. O hospital atua como Hospital Geral Universitário, sendo ligado à Faculdade de Medicina e Escola de Enfermagem da Universidade Federal do Rio Grande do Sul (UFRGS).

Dentro do HCPA, a unidade especificamente considerada para este trabalho é o bloco cirúrgico (BC), que atende somente a casos complexos. Esta unidade está localizada no $13^{\circ}$ andar do prédio em que o HCPA está instalado e atende a pacientes procedentes tanto de leitos de outras unidades do mesmo hospital, quanto pacientes que não estejam hospitalizados, que tenham marcado anteriormente a data da cirurgia e se deslocam até o hospital.

O método utilizado foi de pesquisa qualitativa, com visitas nas instalações do hospital para observação do processo em andamento, análise de relatórios e documentações (Procedimentos Operacionais Padrão - POP) para assim, procurar conhecer como são realizadas as atividades. As observações feitas originaram um questionário estruturado com foco na aplicação dos princípios da produção enxuta de Åhlström (2004), verificando o grau de utilização de cada princípio e possibilidades de melhorias. Juntamente com a equipe de enfermagem responsável pelo bloco, foi 
escolhido um procedimento representativo da unidade para efetuar o mapeamento, que é o procedimento de Ressecção Transuretral de Próstata (retirada, via uretral, da porção da próstata que bloqueia a uretra e o esvaziamento da urina pela bexiga).

Para complementar a análise, foi realizado o mapeamento de processos (MFV) proposto por Womack e Jones (2005). Para fazer o mapeamento de processos, com adaptação para o setor de serviços, foi feita, inicialmente, a listagem das atividades realizadas, com os tempos correspondentes, considerando tanto a perspectiva do bloco cirúrgico quanto a perspectiva do paciente. A partir das listagens de atividades desenvolvidas, foram desenhados mapas de estado atual do processo, também pela perspectiva do $\mathrm{BC}$ e pela perspectiva do paciente.

Os mapas de processos, após finalizados, foram apresentados a alguns dos funcionários envolvidos no processo, para que os mesmos tivessem a oportunidade de avaliar as análises e proposições feitas. As sugestões feitas pela equipe foram consideradas e inseridas no estudo. Além disso, foram utilizadas entrevistas estruturadas para identificar as principais perdas e problemas do setor, em especial no que diz respeito aos princípios enxutos adaptados para o setor de serviços.

Como há grande variação entre as situações de cada procedimento executado no BC, de acordo com cada paciente, foi definido como delimitação a seqüência seguinte para o processo analisado: o paciente faz o diagnóstico com a equipe médica em ambulatório e tem sua cirurgia agendada no BC pelo próprio ambulatório (cirurgia eletiva, ou seja, marcada com antecedência); o paciente ficará 24 horas ou menos internado após a cirurgia; o leito necessário para o paciente está disponível; não há problemas na admissão do paciente para a cirurgia, as quais poderiam causar a suspensão do procedimento. Essa definição se fez necessária para que fosse possível considerar um caso específico de procedimento, evitando variações de situações e alterações de resultados do estudo.

\section{Resultados}

A verificação da situação atual foi iniciada pelo desenho dos processos e da identificação de possibilidades de melhorias nos mesmos. Os Quadros 2 e 3 mostram as listagens de processos do bloco, considerando as perspectivas do hospital e do paciente, as quais foram utilizadas como base para o desenho do mapa do estado atual do BC. As perspectivas do paciente e do hospital foram desenhadas juntas, para que fosse possível verificar os pontos de intersecção entre os processos, o que possibilita a identificação dos pontos de agregação de valor para o paciente e os processos passíveis de melhoria (aqueles que não agregam valor), em especial no que diz respeito aos tempos de execução. 
Quadro 2 - Atividades desenvolvidas durante o processo de Ressecção Transuretral de Próstata

\begin{tabular}{|c|c|c|c|}
\hline $\begin{array}{c}\text { ÁREA / } \\
\text { PROFISSIONAL }\end{array}$ & TEMPO & ORDEM & DESCRIÇÃO \\
\hline $\begin{array}{l}\text { Equipe médica } \\
\text { do ambulatório }\end{array}$ & $1 \mathrm{~h}$ & 1 & $\begin{array}{l}\text { Entra em contato com paciente e confirma a data da cirurgia (que será em } \\
15 \text { dias). Confirma no Sistema (Portal de Cirurgias) a cirurgia do paciente } \\
\text { e solicita material necessário. Médico solicita leito para internação. } \\
\text { Médico solicita internação para uma unidade especial e orienta o paciente } \\
\text { a vir no dia cirurgia, na primeira hora, e se dirija diretamente ao BC. }\end{array}$ \\
\hline $\begin{array}{l}\text { Administrativa } \\
\text { do BC }\end{array}$ & $5 \mathrm{~min}$ & 2 & $\begin{array}{l}\text { Recebe paciente na secretaria do } \mathrm{BC} \text {, verifica documentos coloca junto } \\
\text { ao prontuário, verifica a disponibilidade do leito reservado. } \\
\text { Entrega prontuário na sala de preparo para a Enfermeira e ou Técnica de } \\
\text { Enfermagem e avisa da chegada do paciente. }\end{array}$ \\
\hline $\begin{array}{l}\text { Equipe de } \\
\text { enfermagem da } \\
\text { sala preparação } \\
\text { do BC }\end{array}$ & $10 \mathrm{~min}$ & 4 & $\begin{array}{l}\text { Faz a Admissão do paciente, na sala de preparo, colhendo dados e } \\
\text { verificando alguma intercorrência que possa alterar a cirurgia. Orienta o } \\
\text { paciente sobre o setor. }\end{array}$ \\
\hline $\begin{array}{c}\text { Pessoal de } \\
\text { limpeza }\end{array}$ & $10 \mathrm{~min}$ & 5 & Limpa a sala que foi usada para a cirurgia anterior, retira lixo. \\
\hline $\begin{array}{l}\text { Intrumentadora e } \\
\text { circulante de sala }\end{array}$ & $10 \mathrm{~min}$ & 6 & $\begin{array}{l}\text { Retirada de todo o instrumental e material utilizado na cirurgia anterior e } \\
\text { colocação de material novo. }\end{array}$ \\
\hline $\begin{array}{l}\text { Enfermeira do } \\
\text { BC e médico } \\
\text { anestesista }\end{array}$ & $5 \mathrm{~min}$ & 7 & Busca paciente na sala de preparo e o encaminha para a sala de cirurgia. \\
\hline $\begin{array}{l}\text { Médico } \\
\text { anestesista } \\
\text { enfermeira do } \\
\text { BC }\end{array}$ & $30 \mathrm{~min}$ & 8 & $\begin{array}{l}\text { Conversa com o paciente e avisa o que vai ser feito. Punciona veia para } \\
\text { medicação, realiza a entubação e outros controles e avisa ao cirurgião que } \\
\text { pode iniciar a cirurgia. } \\
\text { Conversa com o paciente e avisa o que vai ser feito. Posiciona o paciente, } \\
\text { faz rapagem de pelos, se for necessário, coloca placa de cautério e auxilia } \\
\text { anestesista. }\end{array}$ \\
\hline Equipe cirúrgica & $10 \mathrm{~min}$ & 10 & $\begin{array}{l}\text { Se prepara para o ato cirúrgico. Escovação e vestimenta, preparo do } \\
\text { paciente com campos cirúrgicos. Inicia a cirurgia depois de confirmar } \\
\text { com Anestesista e equipe de enfermagem. }\end{array}$ \\
\hline Equipe cirúrgica & $2 \mathrm{~h}$ & 11 & $\begin{array}{l}\text { Realiza o ato cirúrgico e o término é com o fechamento da pele e } \\
\text { curativo. }\end{array}$ \\
\hline $\begin{array}{l}\text { Técnico de } \\
\text { enfermagem }\end{array}$ & $30 \mathrm{~min}$ & 12 & $\begin{array}{l}\text { Verifica sinais vitais, posiciona paciente, mede sondas e cateteres, } \\
\text { administra as medicações prescritas. }\end{array}$ \\
\hline $\begin{array}{c}\text { Equipe } \\
\text { anestésica e } \\
\text { enfermeira }\end{array}$ & $15 \mathrm{~min}$ & 13 & $\begin{array}{l}\text { Entregam paciente na sala de recuperação, informam ao anestesista e } \\
\text { enfermeira da sala de recuperação o que ocorreu durante a cirurgia, } \\
\text { salienta algum cuidado se for o caso, informa de alguma intercorrência. }\end{array}$ \\
\hline Equipe cirúrgica & $15 \mathrm{~min}$ & 14 & $\begin{array}{l}\text { Vai até a secretaria do } \mathrm{BC} \text { e dá informações sobre término da cirurgia a } \\
\text { familiares e acompanhantes. }\end{array}$ \\
\hline
\end{tabular}

Fonte: Pesquisa de campo (2008)

Considerando como critério para a geração de valor as situações de preparo do paciente para a cirurgia, ato cirúrgico e encaminhamento do paciente à sala de recuperação, a verificação dos processos pela perspectiva do BC mostra que 50\% das atividades desenvolvidas durante o atendimento ao paciente não agregam valor. As etapas do processo que não são geradoras de valor são referentes às atividades burocráticas, preparo da sala de cirurgia e da equipe cirúrgica.

Embora não seja possível eliminar essas tarefas que não agregam valor, verifica-se que há atividades que são executadas de forma seqüencial que poderiam ser executadas em paralelo com outras, o que reduziria os tempos totais envolvidos no procedimento. Em princípio, essas tarefas 
poderiam ser executadas juntamente, sem que fosse necessária a contratação de funcionários extras para a sua execução, o que torna essas alterações simples de serem executadas.

Quadro 3 - Processo de Ressecção Transuretral de Próstata, pela perspectiva do Paciente

\begin{tabular}{|c|c|c|}
\hline TEMPO & ORDEM & "DESCRIÇÃO \\
\hline $20 \mathrm{~min}$ & 1 & $\begin{array}{l}\text { Recebe ligação do cirurgião confirmando a data da cirurgia. Confirma orientação já dada } \\
\text { sobre jejum, exames médicos e acompanhamento obrigatório de familiar. }\end{array}$ \\
\hline 15 dias & 2 & Aguarda pela data da cirurgia. \\
\hline $5 \mathrm{~min}$ & 3 & No hospital, no dia da cirurgia, apresenta a documentação e o familiar. \\
\hline $10 \mathrm{~min}$ & 4 & Aguarda chamada da equipe de enfermagem para entrar no bloco cirúrgico. \\
\hline $10 \mathrm{~min}$ & 5 & $\begin{array}{l}\text { É chamado pela equipe de enfermagem. É encaminhado para a sala de preparo. É preparado } \\
\text { para a cirurgia. }\end{array}$ \\
\hline $10 \mathrm{~min}$ & 6 & Aguarda, na sala de preparo, ser levado para a sala de cirurgia. \\
\hline $5 \mathrm{~min}$ & 7 & É levado para a sala de cirurgia. \\
\hline $30 \mathrm{~min}$ & 8 & $\begin{array}{l}\text { Enfermeira e Anestesista admitem paciente na sala de cirurgia: verificam vias respiratórias, } \\
\text { fazem preparos específicos, anestesia, etc. }\end{array}$ \\
\hline $10 \mathrm{~min}$ & 9 & Aguarda início da cirurgia (já anestesiado). \\
\hline $2 \mathrm{~h}$ & 10 & Cirurgia é executada. \\
\hline $30 \mathrm{~min}$ & 11 & $\begin{array}{l}\text { Técnico de Enfermagem, verifica sinais vitais, posiciona paciente, mede sondas e cateteres, } \\
\text { administra as medicações prescritas. }\end{array}$ \\
\hline $15 \mathrm{~min}$ & 12 & É levado para a sala de recuperação. \\
\hline $15 \mathrm{~min}$ & 13 & $\begin{array}{l}\text { Enfermeira da sala de Recuperação da notícias pessoalmente, aos familiares ou } \\
\text { acompanhantes, de } 2 \text { em } 2 \text { horas dos pacientes que estão na sala de recuperação. }\end{array}$ \\
\hline
\end{tabular}

Fonte: Pesquisa de campo (2008)

A análise da perspectiva do paciente demonstra que o maior problema existente é o tempo de espera entre a confirmação da data da cirurgia e a sua execução. O paciente aguarda 15 dias para ser operado. Essa etapa não foi alterada, em virtude de que o BC não teria condições de efetuar qualquer modificação neste prazo sem alterar as rotinas de outras unidades do hospital. Como 95\% dos atendimentos efetuados no BC são provenientes de pacientes do Sistema Único de Saúde Pública do Brasil (SUS), ou seja, pela prestação de serviços médicos públicos, a demanda existente é muito maior do que a capacidade de atendimento do BC. Por essa razão, a marcação de cirurgias, que é feita em ambulatórios de atendimento, pode ocorrer até 12 meses antes da data marcada para o procedimento. O prazo de 15 dias de confirmação serve para que o hospital tenha tempo hábil de entrar em contato com os pacientes, confirmar o procedimento no sistema interno do hospital, o qual é utilizado no BC para programar as suas atividades, além de servir para que outras unidades relacionadas (como o Centro de Material, por exemplo, responsável pela preparação de materiais cirúrgicos que são utilizados durantes as cirurgias do BC) possam programar as suas atividades com antecedência. Assim, optou-se por não alterar esse prazo de execução, que deve ser estudado mais profundamente, em conjunto com outras unidades do HCPA.

Uma questão que é relevante de ser mencionada é a referente ao tempo de internação do paciente após o processo cirúrgico. A situação definida para mapeamento delimita o mesmo aos 
casos em que o tempo de internação do paciente é de 24 horas ou menos. Entretanto, quando os pacientes necessitam de internação por mais de 24 horas, há uma etapa a mais no processo, que é a de espera por leito. Nesses casos, mesmo com a cirurgia estando marcada, é possível que não haja leito disponível na data do procedimento, em virtude da não liberação de vagas que estão sendo ocupadas por outros pacientes do HCPA. Quando isso ocorre, o paciente não é operado e precisa voltar para casa e aguardar novo chamado da equipe médica, o que gera grande frustração para o cliente. Isso pode ocorrer em decorrência de que pacientes podem levar mais tempo para se recuperar e receber alta do que o esperado (na sala de recuperação do $\mathrm{BC}$ ou em outros leitos do hospital), além da possibilidade de que leitos sejam liberados na data esperada, mas que, por motivos de urgência ou não verificação do sistema, esses leitos livres sejam ocupados por outros pacientes, que não os do BC.

Outras etapas do atendimento do paciente também não podem ser facilmente alteradas, em função de questões burocráticas do hospital. Nesse sentido, como houve a proposição de alteração da atividade de preparo da equipe médica, o que aceleraria o início da cirurgia, o mapa futuro do paciente muda no sentido de que a atividade de espera desaparece, adiantando todas as etapas seguintes. Assim, entre o mapa atual e o mapa futuro alcança-se uma redução de 20 minutos de tempo total.

Com a identificação das perdas existentes no processo, passou-se para a aplicação do questionário estruturado por princípios e obtiveram-se as constatações apresentadas no Quadro 4. Como resultado, encontram-se os pontos de conflito observados e as sugestões de melhorias que poderiam ser implantadas seguindo-se os princípios da produção enxuta, a fim de melhorar o sistema como um todo.

Quadro 4 - Identificação da Aplicação dos Princípios Enxutos e Sugestões de Melhorias

\begin{tabular}{|l|l|l|l|}
\hline Princípio & Situação atual & Conflitos observados & Sugestões de melhoria \\
\hline \hline
\end{tabular}




\begin{tabular}{|c|c|c|c|}
\hline 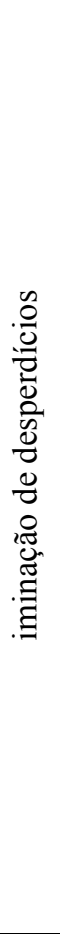 & $\begin{array}{l}\text { - Atividades relacionadas são } \\
\text { colocadas próximas umas das } \\
\text { outras. } \\
\text { - Existem indicadores para } \\
\text { avaliação de tempos de cirurgia e } \\
\text { espera. } \\
\text { - Existe controle de estoque visual. } \\
\text { - Existem listas das salas com } \\
\text { materiais disponíveis em cada uma. } \\
\text { - Existem estimativas de tempo para } \\
\text { as atividades nos POPs } \\
\text { (Procedimentos Operacionais } \\
\text { Padrão). } \\
\text { - Existe um setor de ouvidoria que } \\
\text { leva as reclamações e necessidades } \\
\text { dos pacientes para os gestores. } \\
\text { - O layout específico do processo da } \\
\text { cirurgia é bem desenhado (em U). }\end{array}$ & $\begin{array}{l}\text { - Layout não facilita remoção de } \\
\text { pacientes graves. } \\
\text { - Muitas cirurgias sendo } \\
\text { desmarcadas ou atrasadas. } \\
\text { - Enorme tempo entre a } \\
\text { marcação da cirurgia e a } \\
\text { realização (1 ano). } \\
\text { - Muita burocracia em relação à } \\
\text { looping de papéis para } \\
\text { assinatura. } \\
\text { - O acerto do paciente no setor de } \\
\text { convênios é realizado somente } \\
\text { em cima da hora da cirurgia. } \\
\text { - O atraso nas cirurgias é medido } \\
\text { somente no final, ou seja, se ela } \\
\text { começa atrasada mas acaba } \\
\text { dentro do esperado não é } \\
\text { considerado problema. } \\
\text { - Ocorrem atrasos no início das } \\
\text { cirurgias por falhas na } \\
\text { comunicação e entendimento } \\
\text { entre equipe de anestesia e } \\
\text { equipe médica. }\end{array}$ & $\begin{array}{l}\text { - Tirar o Centro de } \\
\text { Obstetrícia do mesmo andar } \\
\text { (aumentar espaço). } \\
\text { - Médicos estimarem com } \\
\text { mais precisão os tempos de } \\
\text { cirurgia. } \\
\text { - Colocar código de barras } \\
\text { em documentos e deixar } \\
\text { apenas uma assinatura como } \\
\text { obrigatória. } \\
\text { - O acerto do paciente no } \\
\text { setor de convênios poderia } \\
\text { ser feito anteriormente. } \\
\text { - Considerar atraso nas } \\
\text { cirurgias quando elas } \\
\text { começam fora do horário. } \\
\text { - Fazer grupo de trabalho } \\
\text { com equipes de anestesia e } \\
\text { cirúrgica para resolver o } \\
\text { problema de horário de início } \\
\text { de cirurgias. }\end{array}$ \\
\hline
\end{tabular}




\begin{tabular}{|c|c|c|c|}
\hline 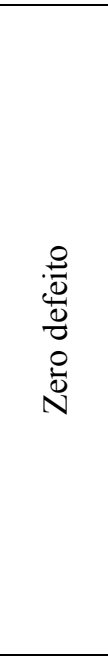 & $\begin{array}{l}\text { - Há dispositivos a prova de falhas: } \\
\text { forma de dobra das roupas para evitar } \\
\text { contaminação, identificação diferentes } \\
\text { de materiais esterilizados, pergunta do } \\
\text { questionário de admissão do paciente } \\
\text { sobre o procedimento, etc. } \\
\text { - Existem métodos padronizados } \\
\text { (POPs). } \\
\text { - Existe uma comissão de } \\
\text { medicamentos que faz a aprovação e } \\
\text { controle de tudo que é utilizado. } \\
\text { - Existe a realização periódica de } \\
\text { pesquisa de satisfação dos pacientes } \\
\text { que é avaliada pelos gestores. } \\
\text { Realizam manutenção programada e } \\
\text { preventiva. }\end{array}$ & $\begin{array}{l}\text { - Sala de isolamento e CTI } \\
\text { fora do bloco, sendo } \\
\text { necessário sair com o paciente } \\
\text { do bloco. } \\
\text { - Não busca conhecimento de } \\
\text { melhores práticas com seu } \\
\text { benchmarking. }\end{array}$ & $\begin{array}{l}\text { - Sala de isolamento mais } \\
\text { próxima do bloco e elevador } \\
\text { próprio para transporte de } \\
\text { paciente para CTI. } \\
\text { - Buscar troca de } \\
\text { conhecimentos com outros } \\
\text { hospitais. }\end{array}$ \\
\hline 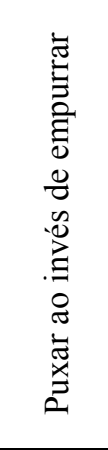 & $\begin{array}{l}\text { - Existe entrega just-in-time de } \\
\text { materiais. } \\
\text { - As entregas por parte do } \\
\text { almoxarifado central são feitas } \\
\text { diariamente. }\end{array}$ & $\begin{array}{l}\text { - O centro de materiais não } \\
\text { conhece muito a respeito de } \\
\text { cada uma das especialidades. } \\
\text { - O contato com fornecedores } \\
\text { é restrito em função de } \\
\text { possibilidade de fraudes. } \\
\text { - Poderia haver mais } \\
\text { comunicação e envolvimento } \\
\text { entre os setores. } \\
\text { - Existem falhas no sistema de } \\
\text { marcação de cirurgias. }\end{array}$ & $\begin{array}{l}\text { - Melhorar a comunicação } \\
\text { entre os setores, implantando } \\
\text { um programa para um setor } \\
\text { conhecer o outro. } \\
\text { - Melhorar comunicação } \\
\text { entre CME e bloco cirúrgico } \\
\text { (telefone não é eficiente). } \\
\text { Software para escala de } \\
\text { cirurgias com atualização on- } \\
\text { line e compra de mais } \\
\text { computadores. }\end{array}$ \\
\hline 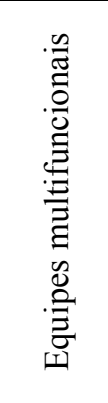 & $\begin{array}{l}\text { - Existem reuniões periódicas para } \\
\text { troca de experiências. } \\
\text { - Treinamentos podem ser solicitados } \\
\text { sempre que necessários ao RH. } \\
\text { - Os líderes são eleitos pelos outros da } \\
\text { equipe. } \\
\text { - Existem vários grupos de estudo } \\
\text { para assuntos específicos com repasse } \\
\text { de informações aprendidas. }\end{array}$ & $\begin{array}{l}\text { - Funções muito diferenciadas } \\
\text { que não permitem rotação de } \\
\text { atividades. } \\
\text { - Não existe nenhum tipo de } \\
\text { rodízio. }\end{array}$ & $\begin{array}{l}\text { - Troca de experiências entre } \\
\text { o bloco e o centro de } \\
\text { materiais com revezamento } \\
\text { de equipes. } \\
\text { Verificar possibilidade de } \\
\text { implantar rodízio de } \\
\text { funcionários em alguns postos } \\
\text { de trabalho (ex.: técnicos de } \\
\text { enfermagem, pessoal da sala } \\
\text { de recuperação, etc.). }\end{array}$ \\
\hline 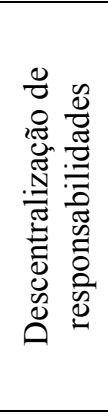 & $\begin{array}{l}\text { - Responsabilidades bem definidas, } \\
\text { padronizadas e documentadas. } \\
\text { - Existem reuniões periódicas entre } \\
\text { funcionários e supervisores e entre os } \\
\text { supervisores e a alta direção. } \\
\text { - Existem check-list de inspeções e } \\
\text { limpezas de salas com rubrica do } \\
\text { responsável. } \\
\text { Os funcionários são incentivados a } \\
\text { identificar e resolver problemas. }\end{array}$ & $\begin{array}{l}\text { - Para alguns procedimentos é } \\
\text { necessária a autorização do } \\
\text { supervisor. }\end{array}$ & $\begin{array}{l}\text { - Fazer uma verificação geral } \\
\text { de quais atividades realmente } \\
\text { precisam de autorização } \\
\text { superior e quais } \\
\text { feitas podem ser } \\
\text { responsabilidade. }\end{array}$ \\
\hline 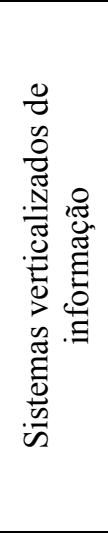 & $\begin{array}{l}\text { - As informações são amplamente } \\
\text { difundidas, chegam a todos os níveis e } \\
\text { todos sabem interpretá-las. } \\
\text { - Existe uma TV com informações de } \\
\text { localização de paciente para } \\
\text { familiares. } \\
\text { - O controle do desempenho das } \\
\text { atividades é feito através das } \\
\text { especificações dos POPs. } \\
\text { - Estão montando o Mapa Estratégico } \\
\text { (BSC). }\end{array}$ & $\begin{array}{l}\text { - O acesso às informações de } \\
\text { cirurgias e troca de horários é } \\
\text { manual e propenso a falhas. } \\
\text { - Informações sobre liberação } \\
\text { de leitos acabam atrasando } \\
\text { procedimentos. } \\
\text { - Não existe um local separado } \\
\text { para informar familiares. } \\
\text { - Lista base de kits para } \\
\text { cirurgias estava desatualizada. }\end{array}$ & $\begin{array}{l}\text { - Software para escala de } \\
\text { cirurgias com atualização on- } \\
\text { line e compra de mais } \\
\text { computadores. } \\
\text { - Melhorar o fluxo de } \\
\text { informação sobre as vagas de } \\
\text { leitos. } \\
\text { - Criação de uma sala } \\
\text { reservada para atendimento a } \\
\text { familiares. } \\
\text { - Fazer atualização e prever } \\
\text { revisão periódica da lista } \\
\text { base de kits para cirurgias. }\end{array}$ \\
\hline
\end{tabular}




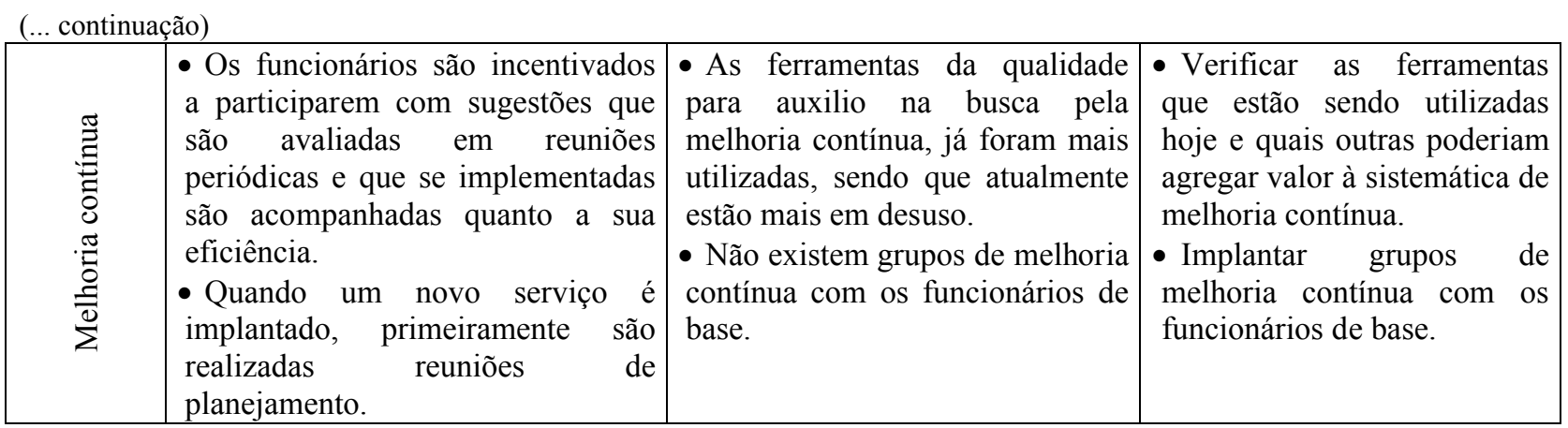

Fonte: Pesquisa de campo (2008)

\section{Discussão}

O estudo da aplicação dos princípios enxutos no Bloco Cirúrgico do HCPA permitiu que fossem verificadas possibilidades de melhorias, tanto na questão da organização burocrática do bloco, quanto na forma como os atendimentos são executados para os pacientes. As atividades desenvolvidas no BC são consideradas puxadas pelo fato de que são desencadeadas a partir do momento em que o paciente chega ao bloco, ou seja, somente com a existência da demanda imediata.

Um exemplo de princípio da produção enxuta que se aplica ao contexto do BC é a eliminação de filas e o tempo de espera do cliente. No caso do HCPA, verificou-se que as filas fazem parte do processo. Pelo fato de a demanda ser extremamente maior do que a capacidade de atendimento do sistema, considerando não somente o próprio hospital, mas todo o sistema público de saúde, a existência de filas está institucionalizada e há pouco que um único hospital possa fazer para mudar a situação, ao menos no que diz respeito aos pacientes que estão em busca de atendimento ou aguardando por um procedimento cirúrgico. Nesse caso, o tempo de espera pode superar os 12 meses. Entretanto, há condições de que o atendimento interno seja melhorado de algumas formas, a fim de reduzir filas para os pacientes que já estão no hospital ou que já estão aguardando pela realização de procedimento.

Ao verificarmos as possibilidades de melhorias com as sugestões de Womack e Jones (2005), é possível concluir que nem todas as proposições dos autores são alcançadas de maneira satisfatória. O primeiro princípio diz que o prestador do serviço deve resolver completamente o problema do cliente, o que é parcialmente verdadeiro. A equipe cirúrgica, dentro da limitação imposta pelas filas de espera pelas cirurgias, faz o possível para que o paciente tenha o melhor atendimento possível, mas certamente o fato de que há uma grande espera para ser operado faz com que o paciente não fique completamente satisfeito.

Assim como o princípio anteriormente discutido, o que fala sobre não desperdiçar o tempo do cliente está relacionado com a fila de espera, que não pode ser resolvida nesse momento. Também 
está relacionado com os momentos de espera dentro do $\mathrm{BC}$, ou antes, da sua entrada, na sala de espera. Essas situações estão sendo estudadas para que os seus tempos sejam reduzidos.

O princípio que trata sobre fornecer exatamente o que o cliente quer, adaptado para a situação do hospital, mostra que o mais importante, em todo o processo de prestação de serviços cirúrgicos, não é a rapidez, mas sim a qualidade do atendimento dos médicos que estão efetuando o ato cirúrgico e dos medicamentos e materiais utilizados. No que se refere a esse item, verificou-se, durante a execução do trabalho, que há rígido controle de materiais e de equipamentos, bem como há grande preocupação com a qualidade do pessoal envolvido em procedimentos, sendo comuns reuniões de equipes e trocas de informações entre os setores e profissionais.

Entregar o produto aonde o cliente quer, o quarto princípio sugerido, não é aplicável à situação estudada. Como não há condições de executar procedimentos cirúrgicos complexos fora do bloco cirúrgico, o cliente deve, necessariamente, se deslocar até o hospital.

A entrega do produto quando o cliente quiser, o quinto princípio, que seria o mais importante, até mesmo para garantir a eficácia do procedimento, bem como para aumentar a qualidade de vida dos pacientes, não está sendo aplicado. Conforme já mencionado, a maior parte dos pacientes são provenientes do sistema público de saúde, sendo que há uma fila de espera maior do que o hospital consegue absorver. Além disso, o BC não tem condições de ser ampliado, por limitações físicas do HCPA como um todo.

Finalmente, em relação ao princípio da redução do número de decisões que o cliente precisará tomar para solucionar o seu problema, o bloco já toma a maior parte das ações necessárias, como manter os familiares sempre informados sobre o estado dos pacientes que estão sendo operados. Além disso, considerando o momento em que o paciente recebe a ligação de confirmação da data da cirurgia, procedimento que é executado fora do $\mathrm{BC}$, o paciente recebe todas as informações necessárias para que se prepare para a cirurgia, não necessitando buscar informações adicionais.

É importante lembrar que, freqüentemente, as soluções que o cliente realmente deseja simplesmente não podem ser implementadas (WOMACK, 2006). Isso não impede, entretanto, que todos os processos sejam constantemente analisados com a intenção de identificar possibilidades de melhorias.

Um grande desafio para os gestores de hoje é sincronizar as necessidades dos indivíduos, das funções, da empresa e do fluxo de valor de forma a produzir o máximo de benefícios, aumentando as oportunidades individuais, a força funcional e o bem estar de todos (SÁNCHEZ; PÉREZ, 2004).

De acordo com a forma de explicitar os princípios de Åhlström (2004), o resultado da aplicação de cada um dos princípios em empresas de serviço é detalhado a seguir:

a) Eliminação de desperdícios - é um princípio bem geral e totalmente aplicável às operações de serviço. Em particular, é bem aplicável aos materiais utilizados nos serviços, no 
caso de hospitais, principalmente na manipulação destes materiais. O princípio pode ser aplicado aos processos de serviço procurando-se eliminar tudo que não agrega valor ao cliente. Geralmente os processos de serviços não são desenhados com muito cuidado. Um importante meio de eliminar desperdícios é através do uso de tecnologia para dar suporte aos processos, pois a tecnologia raramente substitui pessoas em atividades de serviço. Encontrar uma maneira de melhorar o layout a fim reduzir a movimentação desnecessária do paciente é um desafio para reduzir o desperdício de tempo com movimentação. O importante é ver a definição de desperdício da perspectiva de cada operação. Deve-se ter cuidado, pois o que um consumidor enxerga como desperdício outro pode ver como um valor agregado.

b) Zero defeito - é um princípio de fato aplicável aos serviços, pois a idéia de qualidade em serviços é chave. A definição de qualidade em serviços é diferente em manufatura e bem mais complicada, pois o consumidor é parte do processo. Além disso, o esforço de atingir o zero defeito não é realizável nestes serviços onde o cliente está intimamente envolvido, pois os erros são inerentes. Por isso, talvez "zero defeito" não seja o nome ideal para chamar este princípio que reflete a necessidade de se trabalhar com qualidade nos serviços. Apesar disso, as práticas deste princípio de checar os processos ao invés de inspecionar só o produto final são totalmente aplicáveis.

c) Puxar ao invés de empurrar - este princípio é facilmente aplicável aos materiais utilizados nos serviços, mas em processos como os de um hospital, uma falha na entrega de algum material pode ter conseqüências desastrosas, que fazem com que um sistema puramente puxado não seja factível. Os serviços, por definição, são puxados porque não podem ser estocados, têm que ser produzidos à medida que são solicitados. As características dos serviços fazem com que alguns se tornem muito caros para assegurar uma capacidade de atender exatamente a demanda sem formar fila. As únicas atividades que são puxadas no BC são as relativas a equipamentos e limpeza de salas, as quais podem ser efetuadas mesmo antes da chegada do paciente, de acordo com a programação informada no Portal de Cirurgias.

d) Equipes multifuncionais - organizar a força de trabalho em equipes que podem fazer várias tarefas é válido tanto na manufatura quanto nos serviços, sendo que em alguns casos de serviços a competência dos funcionários é mais importante do que em fábricas. Os empregados em empresas de serviço de contato intenso com os consumidores têm um papel crítico em entregar valor a eles. Nos hospitais a legislação e estatutos profissionais impedem a formação de equipes multifuncionais legítimas, pois não há como se ter rotação total entre atividades dos times.

e) Descentralização de responsabilidades -0 princípio da descentralização de responsabilidades àqueles envolvidos em criar valor para o consumidor é certamente 
aplicável em serviços, sendo até mais importante do que na manufatura principalmente em serviços de contato intensivo com consumidores. Os funcionários de frente precisam ter autoridade para tomar decisões quando no encontro com consumidores. A necessidade de decisões rápidas freqüentemente está ligada à qualidade dos serviços e à necessidade dos empregados em tomarem ações corretivas para corrigirem falhas nos serviços. Os funcionários devem ser providos de informações, conhecimento e estrutura de suporte. Apesar disso, estudos mostram que este princípio é mais utilizado na manufatura do que nos serviços

f) Sistemas verticalizados de informação - os serviços precisam ser produzidos à medida que são consumidos, então uma descentralização das informações ajuda muito. Quanto mais geograficamente dispersa uma organização for, mais importante é este tipo de sistema para disseminar as informações de acordo com os objetivos da empresa.

g) Melhoria contínua - este princípio é bem geral e por isso aplicável a serviços, sendo o segundo principal, após o de eliminação de desperdícios. Apesar disso, a quantidade de funcionários envolvidos com ele não é muito expressiva hoje em dia.

\section{Conclusão}

Investir na melhoria de processos visando à eliminação de possíveis desperdícios sejam eles de caráter burocrático, de controle, de retrabalho ou parte daquela atividade que o cliente não deseja e nem quer pagar, é fundamental para que as empresas prestadoras de serviços se mantenham competitivas. Para auxiliar neste sentido, os princípios da produção enxuta e o mapeamento de processos se encaixam muito bem, o que foi verificado com o estudo realizado. Foi possível constatar a aplicabilidade de todos os princípios levantados na literatura, sendo que em diferentes graus de aplicação devido a especificidades do setor hospitalar. O princípio da eliminação de desperdício foi o que apresentou maior potencial de melhorias a serem implantadas.

Outro fator importante verificado foi a necessidade de criação de uma verdadeira cultura sobre os princípios da produção enxuta. O envolvimento de todas as pessoas da organização na busca pela melhoria dos processos é um fator vital para o sucesso da implementação da produção enxuta em serviços.

Como sugestão para trabalhos futuros, propõe-se a elaboração de um modelo de questionário estruturado, com base nos princípios da produção enxuta, para facilitar a verificação do estágio da implantação dos princípios em uma organização de serviços. Sugere-se, também, a realização de estudos sobre os processos cirúrgicos de transplantes de órgãos, que se mostram extremamente complexos em virtude da legislação e da burocracia envolvidas com a doação de órgãos e da 
necessidade de que o processo ocorra com a maior urgência.

\begin{abstract}
The services sector is increasing relevantly in the global economy and the companies must eliminate wastage, reduce costs and improve its processes to keep competitive in this scenario. To improve their processes, the service sector is using the lean production tools and techniques which were mainly used by the industry sector. One example of this is the healthy services companies. Develop a lean value workflow expose the wastage sources and can result in a rearrangement of processes and in a culture change. This article has the objective of diagnose the applicability of lean production principles in a healthy service organization through the processes mapping. The conclusion is that adapting the lean production to improve the quality and the productiveness in the service sector results in relevant improvements.
\end{abstract}

Key Words: lean production, lean service, services management, processes mapping, hospitals.

\title{
Referências
}

ÅHLSTRÖM, P. Lean Service Operations: translating lean production principles to service operations. International Journal of Services Technology and Management: v. 5, n. 5/6, p. 545-564, 2004.

\section{cross ${ }^{\text {ref }}$}

BOWEN, D. E.; YOUNGDAHL, W. E. "Lean" Service: in defense of a production-line approach. International Journal of Service Industry Management, v. 9, n. 3, p. 207-225, 1998.

cross ${ }^{\text {ef }}$

FERRO, J. R., Novas fronteiras de aplicação do sistema Lean em serviços. Lean Institute. Disponível em: $<$ http://www.lean.org.br> Acesso em: 10 Dez. 2008.

FITZSIMMONS, J.A.; FITZSIMMONS, M. Administração de Serviços: operações, estratégia e tecnologia de informação. Porto Alegre: Bookman, 4. ed., 2005.

JONES, D. T. Lean in Delivering Services. Lean Summit 2006. São Paulo, SP. 2006.

MARCHWINSKI, C.; SHOOK, J. Léxico Lean - Glossário ilustrado para praticantes do Pensamento Lean. Lean Institute Brasil. 2003.

ROTHER, M; SHOOK, J. Aprendendo a Enxergar - Mapeando o fluxo de valor para agregar valor e eliminar o desperdício. Lean Institute. Jun 1999.

SÁNCHEZ, A. M.; PÉREZ, M. P. The use of lean indicators for operations management in services. International Journal of Services Technology and Management, v. 5, n. 5/6, p. 465-478, 2004.

cross ${ }^{\text {ref }}$

SWANK, C. K. The Lean Service Machine. Harvard Business Review, v. 81 n.10, p.123-130, 2003.

WOMACK, J. P. Lean Consumption. Lean Summit 2006. São Paulo, SP. 2006.

WOMACK, J. P.; JONES, D. T. From Lean Production to the Lean Enterprise. Harvard Business Review, v. 72, n. 2 , p. $93-103,1994$.

WOMACK, J. P.; JONES, D. T. Lean Consumption. Harvard Business Review, v.83, n. 3, p. 58-69, 2005.

WOMACK, J. P.; JONES, D. T.; ROSS, D. A Máquina que Mudou o Mundo. Rio de Janeiro: Campus, 1992. 


\section{Dados dos autores:}

Nome completo: Lisiane Priscila Roldão Selau

Filiação institucional: Universidade Federal de Pelotas, UFPel

Departamento: Departamento de Matemática e Estatística

Função ou cargo ocupado: Professora Assitente, MSc. em Engenharia de Produção

Endereço completo para correspondência (bairro, cidade, estado, país e CEP): R. Gomes Carneiro, 1, CEP 96010-610, Pelotas, RS

Telefones para contato: (53) 32757569 - 32757577

e-mail: lisianeselau@gmail.com

Nome completo: Mônica Gisele Brancher Pedó

Filiação institucional: Universidade Federal do Rio Grande do Sul, UFRGS

Departamento: Programa de Pós-Graduação em Engenharia de Produção

Função ou cargo ocupado: MSc. em Engenharia de Produção

Endereço completo para correspondência (bairro, cidade, estado, país e CEP): Av. Osvaldo Aranha, 99 - $5^{\circ}$ andar, CEP 90040-020, Porto Alegre, RS

Telefones para contato: (51) 33083491 - 33084292

e-mail: monicapedo@terra.com.br

Nome completo: Daniela dos Santos Senff

Filiação institucional: Universidade Federal do Rio Grande do Sul, UFRGS

Departamento: Programa de Pós-Graduação em Engenharia de Produção

Função ou cargo ocupado: MSc. em Engenharia de Produção

Endereço completo para correspondência (bairro, cidade, estado, país e CEP): Av. Osvaldo Aranha, 99 - $5^{\circ}$ andar, CEP 90040-020, Porto Alegre, RS

Telefones para contato: (51) 33083491 - 33084292

e-mail: danisenff@terra.com.br

Nome completo: Tarcisio Abreu Saurin

Filiação institucional: Universidade Federal do Rio Grande do Sul, UFRGS

Departamento: Programa de Pós-Graduação em Engenharia de Produção

Função ou cargo ocupado: Professor Adjunto, Dr. em Engenharia de Produção

Endereço completo para correspondência (bairro, cidade, estado, país e CEP): Av. Osvaldo Aranha, 99 - $5^{\circ}$ andar, CEP 90040-020, Porto Alegre, RS

Telefones para contato: (51) 33083491 - 33084292

e-mail: saurin@ufrgs.br

Recebido para publicação em: 27/01/2009

Aceito para publicação em: 10/03/2009 